CLINICAL STUDY

\title{
Effect of weight reduction on insulin sensitivity, sex hormone-binding globulin, sex hormones and gonadotrophins in obese children
}

\author{
N H Birkebæk, A Lange, P Holland-Fischer ${ }^{1}$, K Kristensen, S Rittig, H Vilstrup ${ }^{1}$, A Handberg ${ }^{1,2}$ and H Gronbaek $^{1}$ \\ Department of Paediatric, Aarhus University Hospital, Skejby, DK-8200 Aarhus, Denmark and ${ }^{1}$ Medical Department V and ${ }^{2}$ Department of Clinical \\ Biochemistry, Aarhus University Hospital, DK-8000 Aarhus C, Denmark
}

(Correspondence should be addressed to N H Birkebaek; Email: nielbirk@rm.dk)

\begin{abstract}
Objective: Obesity in men is associated with reduced insulin sensitivity and hypoandrogenism, while obesity in women is associated with reduced insulin sensitivity and hyperandrogenism. In children, the effect of obesity and weight reduction on the hypothalamo-pituitary-gonadal axis is rarely investigated. The aim of the present study was to investigate the effect of weight reduction in obese Caucasian children on insulin sensitivity, sex hormone-binding globulin (SHBG), DHEAS and the hypothalamo-pituitary-gonadal axis.

Methods: One hundred and sixteen (65 females) obese children with a median age of 12.3 (7-15) years were examined before and after a 10-week stay at a weight loss camp. Examination included anthropometry and fasting blood samples measuring plasma glucose, serum insulin, SHBG, DHEAS, testosterone, 17ß-oestradiol, FSH and LH.

Results: Body mass index $(\mathrm{BMI})$ decreased $(P<0.01)$, insulin sensitivity and SHBG increased $(P<0.01)$, independent of gender and puberty. The changes in insulin sensitivity and the changes in SHBG correlated significantly $(P<0.01)$ independent of gender, puberty and the changes in BMI. Testosterone increased in boys $(P<0.01)$ and tended to decrease in girls $(P=0.05$, in girls after menarche $(P=0.03))$. FSH increased in boys and girls. LH increased in boys and was unchanged in girls.

Conclusions: During weight loss, insulin sensitivity and SHBG increased significantly in obese children, and the changes in insulin sensitivity and the changes in SHBG correlated significantly independent of gender, puberty and the changes in BMI. There was sexual dimorphism in the changes of testosterone, with the changes in boys towards increased virilisation and the changes in girls towards less virilisation.
\end{abstract}

European Journal of Endocrinology 163 895-900

\section{Introduction}

Obesity and physical inactivity reduce insulin sensitivity and increase the risk of type 2 diabetes mellitus (T2DM) $(1,2)$, and weight reduction increases insulin sensitivity in adults as well as in children $(2,3)$.

Sex hormone-binding globulin (SHBG) has biological functions beyond regulation of sex hormones (4). SHBG levels are negatively correlated with obesity and increase during weight loss in adults (5). Furthermore, SHBG levels are correlated with insulin sensitivity (6), and SHBG is a strong predictor for T2DM in adults $(4,7)$. In children, SHBG levels have proven to correlate negatively with obesity and to correlate positively with insulin sensitivity $(8,9)$. Furthermore, SHBG has been shown to correlate negatively with markers of the metabolic syndrome as dyslipidaemia and hypertension (10-12).
Obesity in men, and particularly visceral obesity, is associated with low testosterone and SHBG $(13,14)$. Low testosterone in men and high testosterone in women are associated with reduced insulin sensitivity $(15,16)$, and predict insulin resistance and incident T2DM in older adults (17). In children undergoing a substantial weight loss during a 1 year programme, testosterone increased in pubertal boys and decreased in prepubertal boys, prepubertal- and pubertal girls (18).

Hypogonadotrophic hypogonadism in men has been found to correlate with obesity and T2DM (19). Obesity in prepubertal and early pubertal girls was associated with reduced overnight LH secretion, while obesity was linked to reduced LH pulse amplitude, but elevated LH pulse frequency, in late pubertal girls (20). In adolescent obese girls with menarche, a reduced ratio between LH and the FSH was observed after weight loss (21). 
Thus, investigations have revealed a negative correlation between obesity and insulin sensitivity, SHBG and testosterone in men. In women, however, obesity correlates negatively with insulin sensitivity and SHBG, but positively with testosterone. The correlations between obesity, insulin sensitivity, SHBG and sex hormones, and the effect of weight reduction on these parameters in obese children have only been sparsely studied.

The aim of the present study was to investigate how weight reduction influences insulin sensitivity and the hypothalamo-pituitary-gonadal (HPG) axis in obese children. We analysed insulin sensitivity, SHBG, sex hormones and gonadotrophins before and after 10-week stay at the weight loss camp (WLC).

\section{Subjects and methods}

\section{Study population}

A total of 116 (51 males and 65 females) obese Caucasian children with a median age of 12.3 (7-15) years were included in the study. Moreover, 25 children who were included did not want a second examination, so they were excluded. Body mass index (BMI) z-scores (22) at inclusion in the study were more than 2 except in one girl with a BMI $z$-score of 1.91 (Table 1). Twenty-four children were prepubertal and 92 children were pubertal. A subgroup of 20 females had had menarche. Children with syndromic or endocrine obesity were excluded. Furthermore, we excluded children with fever and children medically treated due to a chronic condition.

At the WLC, the children attended regular school classes, were physically active at least $1 \mathrm{~h}$ everyday and had a fixed diet plan with focus on reduced intake of calories. Food intake consisted of three main meals and three healthy snacks (fruits etc.) a day. No soft drinks were allowed, and candy was allowed only once a week in small amounts.

\section{Study plan}

The examinations were performed at inclusion into the study, just before attending the WLC and after 10-week stay at the WLC. The children were examined after an overnight fast.
Physical examination included a full objective examination including anthropometry. Waist circumference was measured midway between the lower rib margin and the iliac crest. The children were evaluated as prepubertal or pubertal according to Marshall \& Tanner $(23,24)$. Girls with menarche informed of the month and year of first bleeding. Laboratory examinations included a fasting blood sample and a blood sample $2 \mathrm{~h}$ following an oral glucose tolerance test with ingestion of $1.75 \mathrm{~g}$ glucose $/ \mathrm{kg}$ (maximum $75 \mathrm{~g}$ ). We measured plasma glucose, serum insulin, SHBG, DHEAS, testosterone, $17 \beta$-oestradiol $\left(\mathrm{E}_{2}\right)$, FSH and LH. All blood samples were drawn between 0900 and $1000 \mathrm{~h}$ in the morning.

\section{Laboratory procedures and definitions}

Serum levels of SHBG and DHEAS were measured by the routine laboratory immunometric methods on the Immulite 2000 autoanalyzer using commercial kits (Diagnostic Products Corporation (DPC), Los Angeles, CA, USA). SHBG detection limit was $0.2 \mathrm{nmol} / \mathrm{l}$, and coefficients of variation (CV) was 4.5-5.6\%. DHEAS detection limit was $0.4 \mu \mathrm{mol} / \mathrm{l}$, and $\mathrm{CV}$ was $7.1-7.2 \%$. Serum levels of $\mathrm{E}_{2}$, testosterone, $\mathrm{FSH}$ and $\mathrm{LH}$ were measured by the routine laboratory immunometric methods on the Advia Centaur autoanalyzer using commercial kits (Siemens Healthcare Solutions, Dublin, Ireland). $\mathrm{E}_{2}$ detection limit was $0.05 \mathrm{nmol} / \mathrm{l}$ (functional sensitivity), and $\mathrm{CV}$ was $8.6-10.3 \%$. Testosterone detection limit was $0.35 \mathrm{nmol} / \mathrm{l}$, and CV was $8.2-9.9 \%$. FSH detection limit was $0.3 \mathrm{IU} / \mathrm{l}$, and CV was $4.2-4.5 \%$. LH detection limit was 0.07 IU/l, and CV was $4.5 \%$. Detection limits are reported by the kit manufacturer as 2 s.D. of the zero calibrator except for $\mathrm{E}_{2}$, where functional sensitivity is given. All analytical $\mathrm{CV}$ were determined by the routine laboratory as longterm CV on internal controls. Serum insulin was measured by a two-site immunospecific insulin ELISA (25).

Impaired glucose tolerance was defined as blood glucose level of more than $8 \mathrm{mmol} / \mathrm{l} 2 \mathrm{~h}$ after ingestion of glucose $(1.75 \mathrm{~g} / \mathrm{kg}$, maximum $75 \mathrm{~g})$. The insulin sensitivity index-homeostatic model assessment (ISIHOMA) was calculated as follows: 22.5/(insulin $(\mathrm{mU} / \mathrm{l}) \times$ glucose $(\mathrm{mmol} / \mathrm{l}))(26)$.

Table 1 Baseline characteristics of the 116 obese children participating in the study. Data is presented as median and range.

\begin{tabular}{lllll}
\hline & All & Boys & Girls & P value \\
\hline$n$ & 116 & 51 & 65 & \\
Age (years) & $12.3(7-15)$ & $12.0(8-14)$ & $12.3(7-15)$ & NS \\
Prepubertal $(n)$ & 24 & 16 & 8 & $<0.05^{\mathrm{a}}$ \\
Pubertal $(n)$ & 92 & 35 & 57 & \\
BMI $z$-score & $2.91(1.91-4.57)$ & $3.09(2.14-4.57)$ & $2.80(1.91-3.99)$ & $<0.01$ \\
Waist circumference $(\mathrm{cm})$ & $95(62-124)$ & $97.5(62-121.5)$ & $94(74-124)$ & NS \\
\hline
\end{tabular}

\footnotetext{
${ }^{\mathrm{a} C}$ Comparing number of prepubertal and pubertal girls and boys.
} 


\section{Statistical analysis}

Data are presented as median and range. For comparing dichotomised parameters, a $\chi^{2}$-test was used. For comparing baseline with 10-week parameters, Wilcoxon's non-parametric test for related samples was used, and for independent samples, the Mann-Whitney's $U$ test was applied. Correlation analyses were performed by Spearman's $\rho$. Linear regression analysis was used to test the effect of independent variables on the dependent variable. $P<0.05$ was considered statistically significant. SPSS 13.0 (Chicago, IL, USA) was used for data analyses.

\section{Ethics}

The study was performed in accordance with the ethical principles of the Declaration of Helsinki II. The study protocol was approved by the ethics committee of Region Midtjylland. All children and parents gave their informed written consent.

\section{Results}

Demographic data at inclusion are shown in Table 1. There were slightly more girls in the pubertal group and slightly more boys in the prepubertal group $(P<0.05)$. Boys had higher BMI $z$-scores at inclusion than girls $(P<0.01)$.

BMI decreased with a median of $3.0 \mathrm{~kg} / \mathrm{m}^{2}(0-6.5)$ during the 10-week WLC stay (Table 2). Waist circumference decreased significantly $(P<0.01$; Table 2), and there was significant correlation between $\mathrm{BMI}$ reduction and the changes in waist circumference $(P<0.05)$. No children had T2DM, three children had impaired glucose tolerance at inclusion and one child had impaired glucose tolerance at follow-up. Insulin sensitivity evaluated by ISI-HOMA increased significantly during weight loss $(P<0.01)$, and the increase was independent of gender. Insulin sensitivity increased in the prepubertal children $(P<0.01)$ as well as in the pubertal children $(P<0.01)$. SHBG increased significantly and the increase was independent of gender and puberty $(P<0.01)$. The changes in both SHBG and insulin sensitivity was negatively correlated with the changes in BMI $(r=0.29, P<0.01$ and $r=0.28$, $P<0.01$ respectively). The changes in SHBG and the changes in ISI-HOMA correlated significantly $(r=0.35$, $P<0.01$ ) independent of gender, puberty and the changes in BMI.

Serum testosterone increased significantly during weight loss in boys $(P<0.01)$, and there was a trend towards a reduction in girls $(P=0.05)$. In the subgroup of girls with menarche, testosterone decreased from $1.65(1.0-3.2)$ to $1.55(0.7-2.4)(P<0.03)$. We found no correlation between SHBG and testosterone or between the changes in SHBG during weight loss
Table 2 BMI, waist circumference (WC), ISI-HOMA, SHBG, testosterone, DHEAS and $\mathrm{E}_{2}$ at baseline and after weight reduction. Data is presented as median and range.

\begin{tabular}{|c|c|c|c|}
\hline & Baseline & 10 weeks & $\begin{array}{c}P \\
\text { value }\end{array}$ \\
\hline BMI for all $\left(\mathrm{kg} / \mathrm{m}^{2}\right)$ & 27.5 (22.3-43.9) & $24.5(19.9-39.9)$ & $<0.01$ \\
\hline BMI for boys $\left(\mathrm{kg} / \mathrm{m}^{2}\right)$ & $27.1(23.2-35.7)$ & $23.8(20.0-31.8)$ & $<0.01$ \\
\hline BMl for girls $\left(\mathrm{kg} / \mathrm{m}^{2}\right)$ & $27.9(22.3-43.9)$ & $24.7(19.9-39.7)$ & $<0.01$ \\
\hline WC for all $(\mathrm{cm})$ & $95(62-124)$ & $84(69-109)$ & $<0.01$ \\
\hline WC for boys $(\mathrm{cm})$ & $97(62-121)$ & $86(69-108)$ & $<0.01$ \\
\hline WC for girls $(\mathrm{cm})$ & $94(74-124)$ & $83(69-109)$ & $<0.01$ \\
\hline ISI-HOMA for all & $0.7(0.2-3.7)$ & $1.0(0.3-3.4)$ & $<0.01$ \\
\hline ISI-HOMA for boys & $0.7(0.2-3.0)$ & $1.0(0.4-2.9)$ & $<0.05$ \\
\hline ISI-HOMA for girls & $0.7(0.2-3.7)$ & $1.0(0.3-3.4)$ & $<0.01$ \\
\hline SHBG for all (nmol/l) & $36(10-105)$ & $48(13-129)$ & $<0.01$ \\
\hline SHBG for boys & $38(10-105)$ & $54(19-117)$ & $<0.01$ \\
\hline SHBG for girls & $36(10-84)$ & $46(13-129)$ & $<0.01$ \\
\hline $\begin{array}{l}\text { Testosterone for } \\
\text { all }(\mathrm{nmol} / \mathrm{l})\end{array}$ & $1.3(0.4-12.8)$ & $1.4(0.4-21)$ & NS \\
\hline $\begin{array}{l}\text { Testosterone for } \\
\text { boys }\end{array}$ & $1.3(0.5-12.8)$ & $2.1(0.4-21)$ & $<0.01$ \\
\hline $\begin{array}{l}\text { Testosterone } \\
\text { for girls }\end{array}$ & $1.3(0.4-7.6)$ & $1.2(0.4-5.9)$ & 0.05 \\
\hline $\begin{array}{l}\text { DHEAS for all } \\
\quad(\mu \mathrm{mol} / \mathrm{l})\end{array}$ & $3.0(0.5-9.7)$ & $3.3(0.4-9.0)$ & $<0.01$ \\
\hline DHEAS for boys & $3.3(1.1-9.7)$ & $3.6(0.8-9.0)$ & NS \\
\hline DHEAS for girls & $3.0(0.5-6.2)$ & $3.3(0.4-7.2)$ & $<0.01$ \\
\hline $\mathrm{E}_{2}$ for all $(\mathrm{nmol} / \mathrm{l})$ & $0.15(0.05-0.89)$ & $0.13(0.05-0.87)$ & NS \\
\hline$E_{2}$ for boys & $0.12(0.05-0.50)$ & $0.11(0.05-0.49)$ & NS \\
\hline$E_{2}$ for girls & $0.18(0.05-0.89)$ & $0.19(0.06-0.87)$ & NS \\
\hline
\end{tabular}

and the changes in testosterone, neither when testing the whole population nor when stratifying for gender. In girls, there was a significant negative correlation between the changes in testosterone and the changes in insulin sensitivity $(r=0.39, P<0.01)$. In boys, there was no correlation between the changes in testosterone and the changes in insulin sensitivity. In boys, there was no correlation between the changes in BMI and the changes in testosterone neither when examining all boys, nor when examining the boys with a BMI reduction of more than $3 \mathrm{~kg} / \mathrm{m}^{2}(n=31)$ or boys with a BMI reduction of more than $4 \mathrm{~kg} / \mathrm{m}^{2}(n=10)$. Serum DHEAS was significantly higher after weight loss, but the increase was seen only in girls $(P<0.01)$. DHEAS and testosterone correlated at inclusion $(r=0.41, \quad P<0.01)$ and at follow-up $(r=0.28$, $P<0.01)$, but there was no correlation between the changes in testosterone and the changes in DHEAS during weight loss for the total population or for the individual genders.

Serum $\mathrm{E}_{2}$ did not change significantly in boys or in girls (Table 2). We found no correlation between the changes in SHBG and the changes in $E_{2}$ during weight loss.

FSH increased significantly after weight loss in both boys and girls (Table 3). LH increased significantly in boys $(P<0.01)$, but was unchanged in girls although median LH decreased. In girls, testosterone correlated with LH at inclusion as well as at follow-up. LH/FSH was unchanged in both boys and girls, but there was a 
Table $3 \mathrm{FSH}$, LH and $\mathrm{LH} / \mathrm{FSH}$ ratio at baseline and after weight loss in obese children. Data is presented as median and range.

\begin{tabular}{lllc}
\hline & \multicolumn{1}{c}{ Baseline } & 10 weeks & $\boldsymbol{P}$ value \\
\hline LH for all (IU/I) & $1.2(0.1-13.6)$ & $1.5(0.1-14.6)$ & $<0.03$ \\
LH for boys & $1.0(0.1-3.6)$ & $1.2(0.1-14.6)$ & $<0.01$ \\
LH for girls & $2.3(0.1-13.6)$ & $2.1(0.1-13.7)$ & $\mathrm{NS}$ \\
FSH for all (IU/I) & $2.7(0.3-8.2)$ & $3.4(0.3-11.2)$ & $<0.01$ \\
FSH for boys & $1.5(0.3-7.8)$ & $2.5(0.3-11.2)$ & $<0.01$ \\
FSH for girls & $3.9(0.3-8.2)$ & $4.5(0.3-11.1)$ & $<0.01$ \\
LH/FSH ratio for all & $0.5(0.1-3.7)$ & $0.5(0.1-5.3)$ & $\mathrm{NS}$ \\
LH/FSH ratio for boys & $0.4(0.1-3.7)$ & $0.5(0.1-5.3)$ & $\mathrm{NS}$ \\
LH/FSH ratio for girls & $1.1(0.5-3.2)$ & $0.9(0.2-3.1)$ & $\mathrm{NS}$ \\
\hline
\end{tabular}

tendency to reduced LH/FSH ratio after weight loss in the subgroup of girls with menarche (from 1.1 $(0.5-3.2)$ to $0.9(0.2-3.1),(P=0.16))$. In boys, there was a negative correlation between the changes in BMI and the changes in LH, but no correlation between the changes in BMI and the changes in FSH. In girls, the changes in BMI did not correlate with the changes in $\mathrm{LH}$ or $\mathrm{FSH}$.

\section{Discussion}

In the present study of obese children, we found that weight loss during a 10-week stay at the WLC resulted in increased insulin sensitivity by ISI-HOMA, increased SHBG and sexual dimorphism in changes of testosterone.

The negative correlation between BMI and insulin sensitivity is in accordance with previous studies in children $(1,27,28)$, and our demonstration of a negative correlation between the changes in BMI and the changes in insulin sensitivity is also in accordance with previous investigations in obese children $(3,26,29$, 30). We demonstrated a strong positive correlation between increase in insulin sensitivity and increase in SHBG during weight reduction, independent of gender, puberty and the changes in BMI. In adults, low SHBG has been associated with impaired glucose tolerance and T2DM $(4,6,7)$, and SHBG has been shown to increase during weight reduction (5). In children, cross-sectional studies have demonstrated a positive correlation between SHBG and insulin sensitivity $(8,9)$. One study found a significant increase in SHBG in 19 obese children with 'substantial weight loss' (18), but did not examine a possible correlation with the changes in insulin sensitivity. Data on the correlation between the changes in SHBG and the changes in insulin sensitivity during weight reduction are not available for both children and adults. Our demonstration of a strong correlation between the changes in SHBG and the changes in insulin sensitivity during weight loss corroborates that SHBG may be a good clinical marker of insulin sensitivity as proposed $(4,31)$.

During weight reduction, testosterone increased significantly in boys and tended to decrease in girls, and the subgroup of girls with menarche had the highest decrease in testosterone. Reinehr et al. (18) found the highest increase in testosterone in pubertal boys with the largest weight reduction, but both boys with 'a substantial weight loss' $(n=7)$ and boys without weight loss $(n=14)$ had a significant increase in testosterone. The follow-up period in that study was 1 year, and a physiological increase in testosterone in pubertal boys may be expected. Our follow-up period was only 10 weeks, and the time variable might therefore be negligible. Reinehr et al. (18) also found reduced testosterone in a small group $(n=7)$ of pubertal girls with 'substantial weight reduction', in accordance with our observations. As $44 \%$ of testosterone is SHBG bound (32) and SHBG increased during weight reduction, this may partly explain the increase in total testosterone levels in boys; but we did not find any correlation between the changes in SHBG and the changes in testosterone in both boys and girls. Furthermore, testosterone changed inversely in boys and girls during weight reduction, while the changes in SHBG were independent of gender. Thus, the changes in testosterone levels in boys and girls during weight loss may be explained by other mechanisms rather than solely on an increase in SHBG. We found a general increase in DHEAS during weight loss, but only girls showed a significant increase in DHEAS. The changes in testosterone were different from the changes in DHEAS indicating that the origin of the changes in testosterone was not the adrenal glands. Increased testosterone concentration after weight reduction has also been shown in abdominally obese men (5). In a cross-sectional study of obese men, the less obese had low testosterone but normal LH, while the most obese had low testosterone combined with low LH and low LH pulsatility (33). Our observations of increasing testosterone during weight reduction in boys are in line with the findings in adults, and may be LH driven as LH increased significantly in our population of boys. In girls, we demonstrated a significant decrease in testosterone during weight reduction, and the changes in testosterone were inversely correlated with the changes in insulin sensitivity in agreement with the observations by Sudi et al. (34).

The mechanisms by which obesity affects the HPG axis remain to be clarified (13). We found a significant increase in LH and FSH in boys during weight reduction and an inverse relationship between LH and BMI changes. After gastric bypass and massive weight reduction, testosterone and FSH increased significantly in ten adult males (35). It has been observed that obese men are less fertile compared with non-obese men (13). FSH stimulates spermatogenesis, and the increase in FSH seen in our boys after weight reduction is in agreement with the studies in adults. It has been hypothesised that hypogonadotrophic hypogonadism in men may be the result of insulin resistance of the neurons at the level of the GNRH $(13,36)$. Our results 
with increasing LH and FSH in boys during weight loss in combination with increasing insulin sensitivity corroborate this hypothesis. Furthermore, the changes in BMI correlated negatively to the changes in LH in boys, which may indicate an effect of weight loss independent of pubertal progression. Although the time course between the two examinations was only 10 weeks, progression in puberty may explain some of the increase in the reproductive hormones in boys. In girls, FSH increased significantly during weight loss, LH was unchanged but LH/FSH tended to decrease in girls after menarche; at the same time, testosterone decreased. Wabitsch et al. (21) found reduced testosterone and a reduced LH/FSH ratio after weight loss in 15-year-old girls; Reinehr et al. (18) found significantly reduced testosterone levels in a small population of girls with 'substantial weight loss'. Both studies are in accordance with our observations. It has been hypothesised that insulin may represent a regulatory factor in ovarian androgen secretion as high insulin levels stimulate the enzyme P450c17, causing increased conversion of progesterone to androstenedione, which is then converted to testosterone $(37,38)$. Our results in girls showing increased insulin sensitivity after weight loss and an inverse correlation between the changes in insulin sensitivity and the changes in testosterone are in agreement with this hypothesis. Other hormones such as leptin, adiponectin, resistin, ghrelin and endocannabinoids may also have regulatory functions on the HPG axis in obesity and during weight loss (13). However, the mechanisms remain to be determined.

In summary, during weight reduction, insulin sensitivity and SHBG increased among obese children and adolescents, and the changes in insulin sensitivity and the changes in SHBG correlated significantly independent of gender puberty and the changes in BMI. Furthermore, we demonstrated a sexual dimorphism in changes to testosterone, with the changes in boys towards increased virilisation and the changes in girls towards less virilisation.

\section{Declaration of interest}

The authors declare that there is no conflict of interest that could be perceived as prejudicing the impartiality of the research reported.

\section{Funding}

'Sygekassernes Helsefond (grant number 3092-2006 and grant number 3025-2007)', the 'Rosalie Petersen Foundation', the 'Beckett Foundation (grant number 40105 PV/LS)', ‘Århus Amts Lægekredsforenings Forskningsfond', the 'NOVO Nordic Foundation' and 'Børnefonden' are thanked for financial support.

\section{Author contribution statement}

All authors participated in planning of the project and data collection. N H Birkebaek wrote the manuscript draft and the co-authors revised the manuscript.

\section{Acknowledgements}

Laboratory technician Jane Hansen, Skejby University Hospital, is thanked for helping with the drawing and processing of all blood samples.

\section{References}

1 Sinha R, Fisch G, Teague B, Tamborlane WV, Banyas B, Allen K, Savoye M, Rieger V, Taksali S, Barbetta G, Sherwin RS \& Caprio S. Prevalence of impaired glucose tolerance among children and adolescents with marked obesity. New England Journal of Medicine 2002346 802-810. (doi:10.1056/NEJMoa012578)

2 O'Gorman DJ \& Krook A. Exercise and the treatment of diabetes and obesity. Endocrinology and Metabolism Clinics of North America 200837 887-903. (doi:10.1016/j.ecl.2008.07.006)

3 Vitola BE, Deivanayagam S, Stein RI, Mohammed BS, Magkos F, Kirk EP \& Klein S. Weight loss reduces liver fat and improves hepatic and skeletal muscle insulin sensitivity in obese adolescents. Obesity $2009171744-1748$. (doi:10.1038/oby.2009.171)

4 Ding EL, Song Y, Manson JE, Hunter DJ, Lee CC, Rifai N, Buring JE, Gaziano JM \& Liu S. Sex hormone-binding globulin and risk of type 2 diabetes in women and men. New England Journal of Medicine 2009361 1152-1163. (doi:10.1056/NEJMoa0804381)

5 Niskanen L, Laaksonen DE, Punnonen K, Mustajoki P, Kaukua J \& Rissanen A. Changes in sex hormone-binding globulin and testosterone during weight loss and weight maintenance in abdominally obese men with the metabolic syndrome. Diabetes, Obesity and Metabolism 20046 208-215. (doi:10.1111/j.14628902.2004.00335.x)

6 Golden SH, Dobs AS, Vaidya D, Szklo M, Gapstur S, Kopp P, Liu K \& Ouyang P. Endogenous sex hormones and glucose tolerance status in postmenopausal women. Journal of Clinical Endocrinology and Metabolism 200792 1289-1295. (doi:10.1210/jc.2006-1895)

7 Colangelo LA, Ouyang P, Liu K, Kopp P, Golden SH, Dobs AS, Szklo M, Vaidya D, Cushman M \& Gapstur SM. Association of endogenous sex hormones with diabetes and impaired fasting glucose in men: multi-ethnic study of atherosclerosis. Diabetes Care 200932 1049-1051. (doi:10.2337/dc08-2216)

8 Gascon F, Valle M, Martos R, Ruz FJ, Rios R, Montilla P \& Canete R. Sex hormone-binding globulin as a marker for hyperinsulinemia and/or insulin resistance in obese children. European Journal of Endocrinology 2000143 85-89. (doi:10.1530/eje.0.1430085)

9 Galloway PJ, Donaldson MD \& Wallace AM. Sex hormone binding globulin concentration as a prepubertal marker for hyperinsulinaemia in obesity. Archives of Disease in Childhood 200185 489-491. (doi:10.1136/adc.85.6.489)

10 Sorensen K, Aksglaede L, Munch-Andersen T, AachmannAndersen NJ, Petersen JH, Hilsted L, Helge JW \& Juul A. Sex hormone-binding globulin levels predict insulin sensitivity, disposition index, and cardiovascular risk during puberty. Diabetes Care 200932 909-914. (doi:10.2337/dc08-1618)

11 Oya ID, Schoppen S, Lasuncion MA, Lopez-Simon L, Riestra P, Oya MD \& Garces C. Sex hormone-binding globulin levels and metabolic syndrome and its features in adolescents. Pediatric Diabetes 201011 188-194. (doi:10.1111/j.1399-5448.2009.00559.x)

12 Agirbasli M, Agaoglu NB, Orak N, Caglioz H, Ocek T, Poci N, Salaj A \& Maya S. Sex hormones and metabolic syndrome in children and adolescents. Metabolism 200958 1256-1262. (doi:10.1016/j.metabol.2009.03.024)

13 Mah PM \& Wittert GA. Obesity and testicular function. Molecular and Cellular Endocrinology 2009316 180-186. (doi:10.1016/j. mce.2009.06.007)

14 Nielsen TL, Hagen C, Wraae K, Brixen K, Petersen PH, Haug E, Larsen R \& Andersen M. Visceral and subcutaneous adipose tissue assessed by magnetic resonance imaging in relation to circulating androgens, sex hormone-binding globulin, and luteinizing hormone in young men. Journal of Clinical Endocrinology and Metabolism 2007 92 2696-2705. (doi:10.1210/jc.2006-1847) 
15 Hauner H, Ditschuneit HH, Pal SB, Moncayo R \& Pfeiffer EF. Fat distribution, endocrine and metabolic profile in obese women with and without hirsutism. Metabolism 198837 281-286. (doi:10.1016/0026-0495(88)90109-6)

16 Pitteloud N, Mootha VK, Dwyer AA, Hardin M, Lee H, Eriksson KF, Tripathy D, Yialamas M, Groop L, Elahi D \& Hayes FJ. Relationship between testosterone levels, insulin sensitivity, and mitochondrial function in men. Diabetes Care 200528 1636-1642. (doi:10. 2337/diacare.28.7.1636)

17 Oh JY, Barrett-Connor E, Wedick NM \& Wingard DL. Endogenous sex hormones and the development of type 2 diabetes in older men and women: the Rancho Bernardo study. Diabetes Care 200225 55-60. (doi:10.2337/diacare.25.1.55)

18 Reinehr T, de SG, Roth CL \& Andler W. Androgens before and after weight loss in obese children. Journal of Clinical Endocrinology and Metabolism 200590 5588-5595. (doi:10.1210/jc.2005-0438)

19 Dhindsa S, Prabhakar S, Sethi M, Bandyopadhyay A, Chaudhuri A \& Dandona P. Frequent occurrence of hypogonadotropic hypogonadism in type 2 diabetes. Journal of Clinical Endocrinology and Metabolism 200489 5462-5468. (doi:10.1210/jc.2004-0804)

20 McCartney CR, Prendergast KA, Blank SK, Helm KD, Chhabra S \& Marshall JC. Maturation of luteinizing hormone (gonadotropinreleasing hormone) secretion across puberty: evidence for altered regulation in obese peripubertal girls. Journal of Clinical Endocrinology and Metabolism 200994 56-66. (doi:10.1210/jc. 2008-1252)

21 Wabitsch M, Hauner H, Heinze E, Bockmann A, Benz R, Mayer H \& Teller W. Body fat distribution and steroid hormone concentrations in obese adolescent girls before and after weight reduction. Journal of Clinical Endocrinology and Metabolism 1995 80 3469-3475. (doi:10.1210/jc.80.12.3469)

22 Nysom K, Molgaard C, Hutchings B \& Michaelsen KF. Body mass index of 0 to 45-y-old Danes: reference values and comparison with published European reference values. International Journal of Obesity and Related Metabolic Disorders 200125 177-184. (doi:10.1038/sj.ijo.0801515)

23 Marshall WA \& Tanner JM. Variations in pattern of pubertal changes in girls. Archives of Disease in Childhood $1969 \mathbf{4 4}$ 291-303. (doi:10.1136/adc.44.235.291)

24 Marshall WA \& Tanner JM. Variations in the pattern of pubertal changes in boys. Archives of Disease in Childhood 197045 13-23. (doi:10.1136/adc.45.239.13)

25 Andersen L, Dinesen B, Jorgensen PN, Poulsen F \& Roder ME. Enzyme immunoassay for intact human insulin in serum or plasma. Clinical Chemistry $199339578-582$.

26 Reinehr T, Kiess W, Kapellen T \& Andler W. Insulin sensitivity among obese children and adolescents, according to degree of weight loss. Pediatrics 2004114 1569-1573. (doi:10.1542/peds. 2003-0649-F)

27 Ten S \& Maclaren N. Insulin resistance syndrome in children. Journal of Clinical Endocrinology and Metabolism 200489 2526-2539. (doi:10.1210/jc.2004-0276)
28 Viner RM, Segal TY, Lichtarowicz-Krynska E \& Hindmarsh P. Prevalence of the insulin resistance syndrome in obesity. Archives of Disease in Childhood 200590 10-14. (doi:10.1136/adc.2003. 036467)

29 Rohrer TR, Rizzo VF, Cäsar JJ, Muelbredt O, Sprengart S, Gortner L \& Stierkorb E. Changes in hepatic risk factors, metabolic variables, body composition, and physical fitness in obese children after a one-year weight loss program. Journal of Pediatric Endocrinology and Metabolism 200821 837-845.

30 Shalitin S, Ashkenazi-Hoffnung L, Yackobovitch-Gavan M, Nagelberg N, Karni Y, Hershkovitz E, Loewenthal N, Shtaif B, Gat-Yablonski G \& Phillip M. Effects of a twelve-week randomized intervention of exercise and/or diet on weight loss and weight maintenance, and other metabolic parameters in obese preadolescent children. Hormone Research 200972 287-301. (doi:10.1159/000245931)

31 Eyzaguirre F \& Mericq V. Insulin resistance markers in children. Hormone Research 200971 65-74. (doi:10.1159/000183894)

32 Diver MJ. Analytical and physiological factors affecting the interpretation of serum testosterone concentration in men. Annals of Clinical Biochemistry 200643 3-12. (doi:10.1258/ $000456306775141803)$

33 Giagulli VA, Kaufman JM \& Vermeulen A. Pathogenesis of the decreased androgen levels in obese men. Journal of Clinical Endocrinology and Metabolism 199479 997-1000. (doi:10. 1210/jc.79.4.997)

34 Sudi KM, Gallistl S, Borkenstein MH, Payerl D, Aigner R, Moller R \& Tafeit E. Effects of weight loss on leptin, sex hormones, and measures of adiposity in obese children. Endocrine $2001 \mathbf{1 4}$ 429-435. (doi:10.1385/ENDO:14:3:429)

35 Reis LO, Favaro WJ, Barreiro GC, de Oliveira LC, Chaim EA, Fregonesi A \& Ferreira U. Erectile dysfunction and hormonal imbalance in morbidly obese male is reversed after gastric bypass surgery: a prospective randomized controlled trial. International Journal of Andrology 200933 736-744. (doi:10.1111/j.13652605.2009.01017.x)

36 Dandona P, Dhindsa S, Chaudhuri A, Bhatia V, Topiwala S \& Mohanty P. Hypogonadotrophic hypogonadism in type 2 diabetes, obesity and the metabolic syndrome. Current Molecular Medicine 20088 816-828. (doi:10.2174/1566524087867 33658)

37 Poretsky L. On the paradox of insulin-induced hyperandrogenism in insulin-resistant states. Endocrine Reviews 199112 3-13. (doi:10.1210/edrv-12-1-3)

38 Nestler JE \& Jakubowicz DJ. Decreases in ovarian cytochrome P450c17 alpha activity and serum free testosterone after reduction of insulin secretion in polycystic ovary syndrome. New England Journal of Medicine 1996335 617-623. (doi:10.1056/ NEJM199608293350902)

Received 21 August 2010

Accepted 9 September 2010 